\title{
Pulmonary Leiomyoma in a Dromedary Camel (Camelus Dromedarius)
}

\author{
Gamal Wareth and Shawky Ahmed Moustafa \\ Department of Pathology, Faculty of Veterinary Medicine, Benha University, Egypt
}

Correspondence should be addressed to: Gamal Wareth; gamalwareth@daad-alumi.de

Received 9 April 2013; Accepted 16 May 2013; Published 24 June 2013

Academic Editor: Özlem Özmen

Copyright (C) 2013 Gamal Wareth and Shawky Ahmed Moustafa. Distributed under Creative Commons CC-BY 3.0

\begin{abstract}
During post-slaughter inspection of dromedary camel (Camelus dromedarius), two cases of leiomyoma were described in an eight and ten years old male camels. The neoplastic masses involved in the visceral pleura of one camel and lung tissue of another. Histopathologic features revealed proliferated neoplastic cells, resembling the smooth muscle cells, in the pleura and adjacent pulmonary tissue. The tumor masses appeared as circumscribed area of interlacing bundles of smooth muscle cells arranged in various directions and surrounded by connective tissue capsule. Moreover, the adjacent alveoli exhibited areas of atelectasis and emphysema. The origin of leiomyoma was not determined, but it was suggested that the neoplastic cells originated from smooth muscle layer of the pleural blood vessels.
\end{abstract}

Keywords: Leiomyoma, Dromedary camel, Lung, Egypt.

\section{Introduction}

Although neoplastic conditions are infrequently reported in camels (Ramadan, 1994), it is supposed that Camelids are susceptible to all the various tumor types that affect domestic animals. Bronchoalveolar adenocarcinoma (Gameel et al., 1998, Taha et al., 2007), renal cell carcinoma (Vitovec, 1982), salivary fibroadenocarcino-sarcoma (Ramadan et al., 2001), multicentric schwannoma (Khodakaram-Tafti and Khordadmehr, 2011), corneal papilloma (Kilıc et al., 2010), mammary and pulmonary carcinoma (Bryant et al., 2007), chondrosarcoma (Janardhan et al., 2011), seminoma and cholangiocarcinoma (Birincioglu et al., 2008), peripheral primitive neuroectodermal tumour (Weiss and Walz, 2009), multicentric t-cell lymphoma (Simmons et al., 2005) have been reported in the dromedary camel.

The classification of lung neoplasm is slightly more difficult due to the possibilities of epithelium and mesenchymal metaplasia and occurrence of the intermediate or mixed forms. Leiomyoma is a benign tumor of smooth muscle cell primarily arising from the musculature tubular and hollow organs, such as the gastrointestinal, urinary, and genital tracts (Mobini and Kufuor-Mensah, 1987). Leiomyoma is a rare disease though to be derived from uterine leiomyoma. Despite leiomyoma is histological benign tumor, it has the possibility to metastasize

Cite this Article as: Gamal Wareth and Shawky Ahmed Moustafa (2013), "Pulmonary Leiomyoma in a Dromedary Camel (Camelus Dromedarius)," International Journal of Veterinary Medicine: Research \& Reports, Vol. 2013 (2013), Article ID 773813, DOI: 10.5171/2013.773818 
to distant sites such as pelvic and retroperitoneal lymph nodes, omentum, inferior vena cava, right atrium, muscular tissue of the limb and the lung (Funakoshi et al., 2004). The current article documents the first case of pulmonary leiomyoma in camels.

\section{Case History}

During inspection of camel, which slaughtered at the Cairo Abattoir; Egypt. After slaughter, all tissues were examined macroscopically, and the lung tissues were brought to Benha University, Faculty of Veterinary Medicine and department of Pathology for histopathological examination. The tissue samples for histopathology were fixed in 10\% neutral buffered formalin, routinely processed, 5$\mu \mathrm{m}$ sectioned, and stained with Hematoxylin and Eosin (HE). Selected sections were stained by van Gieson's stain (Culling et al., 1985) .

\section{Result}

Two cases were detected microscopically as leiomyoma. The first case was observed in the visceral pleura and revealed thickening of the pleural tissue with proliferation of neoplastic cells, resembling the smooth muscle cells, in the pleura and adjacent pulmonary tissue (Fig. 1). While the second case was detected in the pulmonary tissue and appeared as circumscribed area of interlacing bundles of well-differentiated smooth muscle cells with minimal fibrous stroma, arranged in various directions and surrounded by connective tissue capsule (Fig. 2,3). The neoplastic cells were spindle cells with indistinguishable cytoplasmic borders and elongate, blunt-ended cigar shaped nuclei, no pleomorphism or mitotic activity was observed. The neoplastic mass gave positive reaction by Van-Gieson stain and appeared well differentiated from the surrounding connective tissue capsule (Fig. 4). Moreover, the adjacent alveoli revealed areas of atelectasis and emphysema.

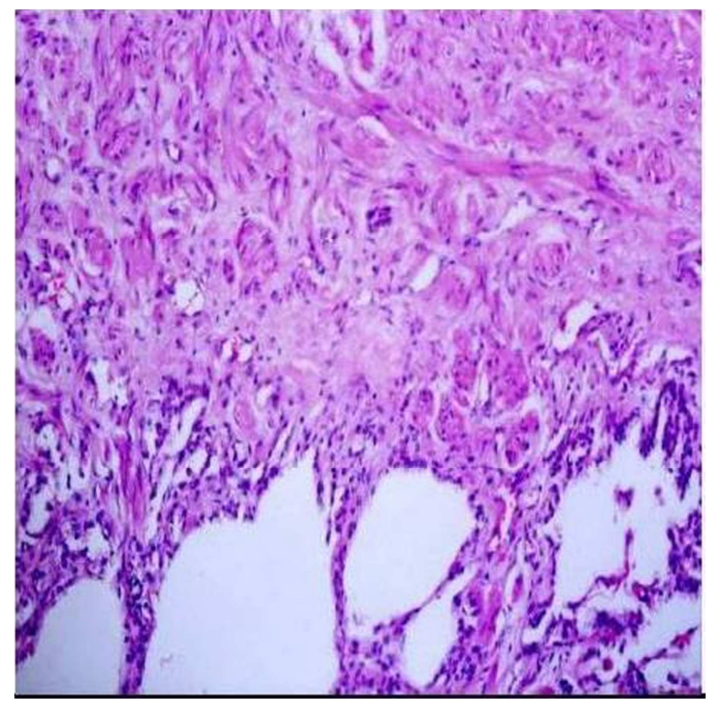

Fig. (1): Lung of Camel Showing Leiomyoma Appeared as Thickening of the Pleural Tissue with Proliferation of Neoplastic Cells; Resembling the Smooth Muscle Cells in Pulmonary Tissue (H\&E Stain x200). 


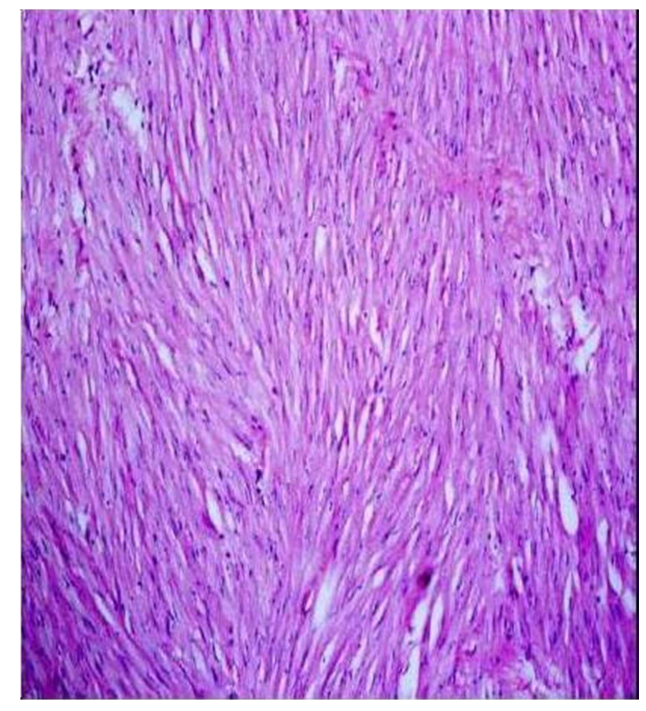

Fig. (2): Lung of Camel Showing Leiomyoma in the Form of Interlacing Bundles of Smooth Muscle Cells Arranged in Various Directions (H\&E Stain x200)

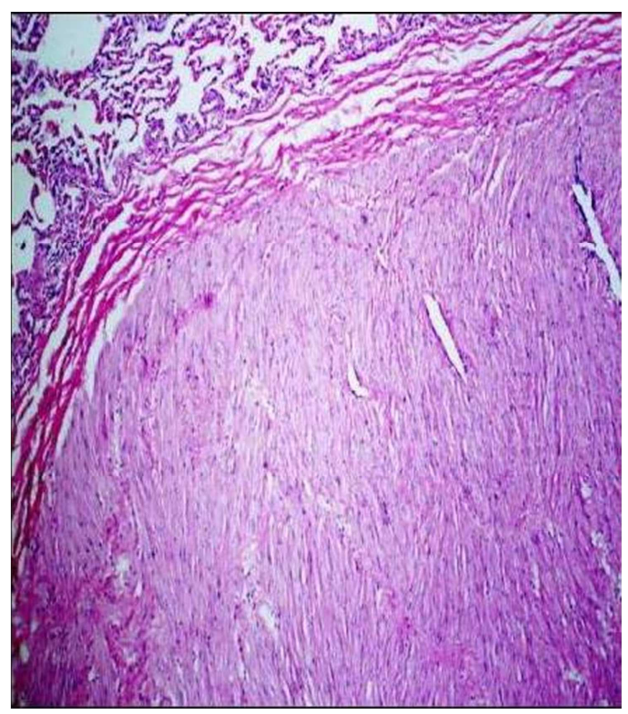

Fig. (3): Lung of Camel Showing Leiomyoma Appeared as Circumscribed Area of Interlacing Bundles of Smooth Muscle Cells Surrounded by Connective Tissue Capsule (H\&E Stain x100). 


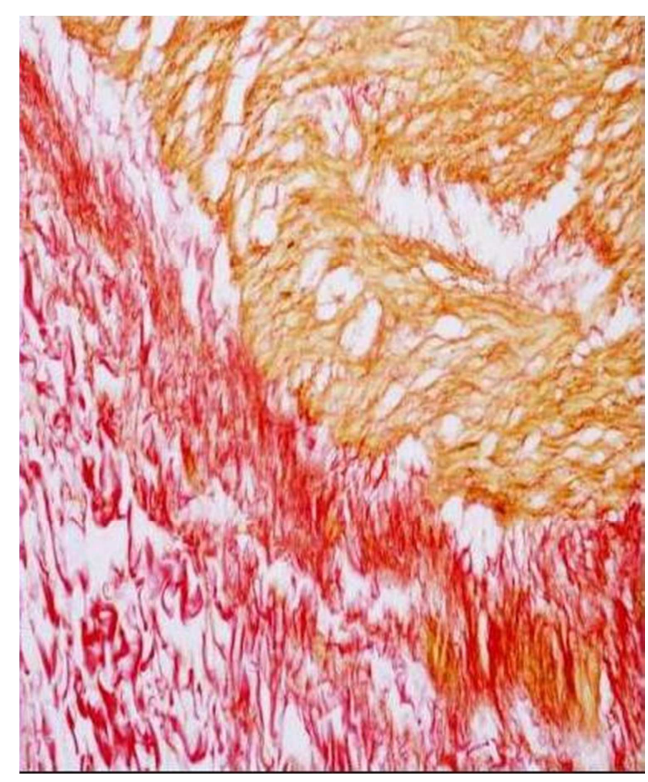

Fig. (4): Lung of Camel Showing Leiomyoma (Van-Gieson Stain x200)

\section{Discussion}

Benign pulmonary tumors are mostly single and generally asymptomatic. Among benign lung lesions leiomyomas are extremely rare (Burkhardt et al., 1981). It is assumed that Camelids are susceptible to all the various tumour types that affect domestic ungulates. Pulmonary leiomyoma described her is the primary. The microscopic examination of the camels' lungs showed presence of two cases of singular leiomyomatous lesions, one observed in the pleura and revealed thickening of the pleural tissue with proliferation of neoplastic cells resembling the smooth muscle cells. While the other case was detected in the pulmonary tissue and surrounded by connective tissue capsule; the adjacent alveoli revealed areas of atelectasis and emphysema. Our results are partially in agreement with (Lopez et al., 1997) who found anal leiomyoma in 2year-old heifer characterized by interlacing bundles of well-differentiated smooth muscle cells with abundant cytoplasm, irregular fusiform nuclei with vesiculated chromatin and scarce mitotic figures.

The tumors reported here was considered as benign tumor due to lack of the characteristic features associated with malignancy, including cellular pleomorphism, multinucleation, poor differentiation of fibers and hyperchromic nuclei with many mitotic figures and necrosis which may be evident grossly and microscopically (Swalec et al., 1989). Leiomyoma has been previously reported in a wide variety of animal species, include dogs, cats, humans, horses, cattle, sheep, and goats (Mobini and Kufuor-Mensah, 1987). In a previous study, two cases of leiomyoma were recorded in camel's uteri during an abattoir survey in Egypt (Moustafa et al., 2004); but have not been previously described in camels lung. In domestic animals, smooth muscle tumors arising within the respiratory tract are extremely rare, however, leiomyoma is still the most common type of gastrointestinal or genital tract stromal tumor (Meuten, 2002). Previous studies conducted with the pathological affections of camel's lung revealed rare neoplastic growth in the lung of these animals. (Taha et al., 2007) found one case of bronchoalveolar adenocarcinoma in lung tissues characterized by tall and differentiated cells with basely located nuclei, form sheets and glands, and secrete mucin. Nevertheless, leiomyoma was not previously recorded in the lung of camels according to available literature. Leiomyomas reported several times in the bovine reproductive tract (Saiyari et al., 
1994), in esophagus and in rectum (Singh et al., 1988, Rajurkar et al., 1995, Lopez et al., 1997). Locally invasive intestinal leiomyomas and leiomyosarcomas were reported in Equine (Haven et al., 1991). In women and bitches, leiomyomas are among the most common reproductive tumors and are highly estrogen dependent in both species (Greenberg et al., 1993). Benign metastasizing leiomyoma is a very rare disease in which tissue from a benign uterine leiomyoma is detected as multiple nodules or as a solitary nodule in the lungs (Naito et al., 2011). Pathological comparison between the pulmonary leiomyoma and the original uterine tumor should provide confirmatory evidence but the immunohistochemical staining and the past history of uterine leiomyoma were not available. Although the origin of the tumor was not determined in this study; we suggested that, the neoplastic cells were originated from smooth muscle layer of the pleural blood vessels.

\section{References}

Birincioglu, S. S., Avci, H. \& Aydogan, A. (2008). "Seminoma and Cholangiocarcinoma in an 18-Year-Old Male Camel," Turkish Journal of Veterinary and Animal Sciences, 32, 141-144.

Bryant, B., Portas, T. \& Montali, R. (2007). "Mammary and Pulmonary Carcinoma in a Dromedary Camel (Camelus Dromedarius)," Australian Veterinary Journal 85, 59-61.

Burkhardt, A., Otto, H. F. \& Kaukel, E. (1981). "Multiple Pulmonary (Hamartomatous?) Leiomyomas: Light and Electron Microscopic Study," Virchows Arch [Pathol Anat] 394, 133-141.

Culling, C. F. A., Allison, R. T. \& Barr, W. T. (1985). Cellular Pathology Technique. 4th Edn., Butterworth \& Co. (Publ.). Ltd., London., 269-270.

Funakoshi, Y., Sawabata, N., Takeda, S., Hayakawa, M., Okumura, Y. \& H., M. (2004). "Pulmonary Benign Metastasizing
Leiomyoma from the Uterus in a Postmenopausal Woman: Report of a Case," Surg Today, 34, 55-57.

Gameel, A. A., Hegazy, A. \& Yassein, N. (1998). "Primary Broncho-Alveolar Adenocarcinoma in a Dromedary Camel (Camelus Dromedarius)," Veterinary record, 142, 252.

Greenberg, M. D., Robinson, T. \& Rbirrer, R. (1993). "Vaginal Bleeding Secondary to an Aborting Uterine Leiomyoma," The American Journal of Emergency Medicine, $11,40-42$.

Haven, M. L., Rottman, J. B. \& Bowman, K. F. (1991). "Leiomyoma of the Small Colon in a Horse," Veterinary Surgery, 20, 320-322.

Janardhan, K. S., Ganta, C. K., Andrews, G. A. \& Anderson, D. E. (2011). "Chondrosarcoma in a Dromedary Camel (Camelus Dromedarius)," Journal of Veterinary Diagnostic Investigation, 23, 619 -622 .

Khodakaram-Tafti, A. \& Khordadmehr, M. (2011). "Multicentric Fibromyxoid Peripheral Nerve Sheath Tumor (Multicentric Schwannoma) in a Dromedary Camel (Camelus Dromedarius): Morphopathological,

Immunohistochemical, and Electron Microscopic Studies," Veterinary Pathology, 48, 1180-1184.

Kilic, N., Toplu, N., Aydog.An, A., Yaygingu, R. \& Ozsoy, S. U. Y. (2010). "Corneal Papilloma Associated with Papillomavirus in a One-Humped Camel (Camelus Dromedarius)," Veterinary Ophthalmology, 13, 100-102.

Lopez, M. J., Prichard, M. \& Steinberg, H. (1997). "Anal Leiomyoma in a Holstein Heifer," The Canadian Veterinary Journal 38, 377-378.

Meuten, D. J. (2002). Tumors in Domestic Animals. Fourth Edition, Iowa State Press, A Blackwell Publishing Company, 2121 State Avenue, Ames, Iowa 50014. 
Mobini, S. \& Kufuor-Mensah, E. (1987). Leiomyoma of the Cervix in a Cow. Compend Contin Educ Prac Vet 9, F222F223.

Moustafa, S. A., Tantawy, A. A. \& Ibrahim, M. F. (2004). An Abattoir Survey of Female Genital Disorders of Camels (Camelus Dromedaries) In Kalyoubia, Egypt. 1rst Ann. Confr., Fvm., Moshtohor, Sept, 2004.

Naito, M., Kobayashi, T., Yoshida, M., Fujiwara, K., Onishi, M., Fujiwara, A., Takagi, T., Kobayashi, H., Gabazza, E. C., Takei, Y. \& Taguchi, O. (2011). "Solitary Pulmonary Nodule of Benign Metastasizing Leiomyoma Associated with Primary Lung Cancer: A Case Report," Journal of Medical Case Reports 5, 500.

Rajurkar, S. R., Rajurmar, R. R. \& Moregaonkary, S. D. (1995). "Leiomyoma of Oeophasgus in Non Descript Bullock: A Case Report," Indian Veterinary Journal, 72, 511-513.

Ramadan, R. O. (1994). 'Cysts and Neoplastic Conditions,' In Surgery and Radiology of the Dromedary Camel, 1st Ed. R.O.Ramadan, King Faisal University, Al Ahsa, Saudi Arabia.

Ramadan, R. O., Hegazy, A. A., Ali, A. S. \& Abdin-Bey, M. R. (2001). "Salivary FibroAdenocarcino-Sarcoma in a Dromedary Camel (Camelus Dromedarius)," Scientific Journal of King Faisal University (Basic and Applied Sciences) 2, 71-76.

Saiyari, M., Nadda, H. \& Gooraninejad, S. (1994). 'Leiomyoma in the Vagina of a Cow,' Indian Vet J 71, 842-843.

Simmons, H. A., Fitzgerald, S. D., Kiupel, M., Rost, D. R. \& Emery, R. W. (2005). "Multicentric T-Cell Lymphoma in a Dromedary Camel (Camelus Dromedarius)," Journal of Zoo and Wildlife Medicine, 36, 727-729.

Singh, P., Sharma, D., Kumar, K. \& Chandna, I. (1988). "Leiomyoma in the Rectum of a Murrah Buffalo-A Case Report," Indian Veterinary Journal, 65, 821-822.
Swalec, K. M., Smeak, D. D. \& Baker, A. L. (1989). "Urethral Leiomyoma in a Cat," Journal of the American Veterinary Medical Association, 7, 961.

Taha, K., Shalaby, A., Sami, M. B. \& Deeb, S. (2007). "Pathological Studies on the Association of Pneumonia and Kidney Affections in Camels (Camelus Dromedaries)," Egypt. J. Comp. Path. \& Clinic. Path., 20, 235- 262.

Vitovec, J. (1982). "Renal Cell Carcinoma in a Camel (Camelus Dromedarius)," Veterinary Pathology Online, 19, 331-333.

Weiss, R. \& Walz, P. H. (2009). "Peripheral Primitive Neuroectodermal Tumour in a Lumbar Vertebra and the Liver of a Dromedary Camel (Camelus Dromedarius)," Journal of Comparative Pathology, 141, 182-186. 